University of Wollongong

Research Online

Faculty of Education - Papers (Archive)

Faculty of Arts, Social Sciences \& Humanities

$1-1-2005$

\title{
Re-organising and integrating the knowledge bases of initial teacher education : the knowledge building community program
}

Julie Kiggins

University of Wollongong, jkiggins@uow.edu.au

Brian Ferry

University of Wollongong, bferry@uow.edu.au

Brian L. Cambourne

University of Wollongong, bcambrn@uow.edu.au

Follow this and additional works at: https://ro.uow.edu.au/edupapers

Part of the Education Commons

\section{Recommended Citation}

Kiggins, Julie; Ferry, Brian; and Cambourne, Brian L.: Re-organising and integrating the knowledge bases of initial teacher education : the knowledge building community program 2005, 75-94.

https://ro.uow.edu.au/edupapers/557

Research Online is the open access institutional repository for the University of Wollongong. For further information contact the UOW Library: research-pubs@uow.edu.au 


\title{
Re-Organising And Integrating The Knowledge Bases Of Initial Teacher Education: The Knowledge Building Community Program
}

\author{
Julie Kiggins, Brian Cambourne \& Brian Ferry \\ University of Wollongong
}

\begin{abstract}
In a Report submitted to the NSW government in 2000, Gregor Ramsay made a claim that should challenge pre-service teacher educators in all Western democracies:

"...it is possible to reorganise the knowledge bases of undergraduate teacher education subjects so that they are more integrated with school and classroom culture, and therefore more relevant, more meaningful, better appreciated by student teachers, with less duplication across subject areas" (Ramsay, 2000, p57)

While such rhetoric sounds appealing, it begs the question of how pre-service teacher educators might realise such rhetoric in practice, given the entrenched transmission of information + practicum model of program delivery inherent in most western universities.

In this chapter we will describe how one team of university -based pre-service teacher educators reorganised the knowledge bases of the primary teacher education course by forgoing compulsory lectures, tutorials and exams to create a knowledge building community which had a strong identity, which was professionally empowered enough to take control of its own learning. We shall describe the "nuts and bolts" of the reorganization process.
\end{abstract}

\section{Part 1. The context of the teacher education program}

Reviews of beginning teachers over the past 80 years continually identify a number of key skills that are not well developed by traditional preparation programs. These include: student discipline, motivating students, dealing with individual differences, insufficient and/or inadequate resources, organisation of class work, assessing student work, and relationships with parents (Koetsier \& Wubbels, 1995; Commonwealth of Australia, 2002). Interviews conducted with final year preservice teachers report that they leave university with feelings of being under-prepared for life in classrooms and confused by what confronts them when they arrive at schools (Armour and Booth, 1999). Further, the schools, that employ beginning teachers, claim that a majority of recent graduates are unaware of how classroom cultures operate and find it difficult to transfer what they've studied at university into effective classroom practice (MACQT, 1998; Vinson, 2002). The Ramsey (2000) review of teacher education in NSW supported these findings and also asserted that preservice teachers do not understand how classroom practice produces effective student learning

Hoban (1999) asserts that many teacher education courses present a fragmented view of learning and this hinders preservice teacher development into flexible, progressive teachers. Studies of learning in schools and universities support this view and regularly assert that knowledge is presented in a fragmented and decontextualised way (Entwhistle, Entwhistle \& Tait, 1993). As a result essential knowledge is not retrieved when it is required in real-life situations because there is no link to the situation in which it applies (Bransford et al, 1990).

The Ramsey (2000) review of teacher education in NSW supported these findings and recommended that preservice teachers receive quality classroom-based experience supervised by an accredited teacher mentor. However, providing more extensive 
classroom-based experience is no guarantee of quality (Darling-Hammond, 1999) and Ramsey (2000) admitted that school-based practical experience often consists of a series of isolated, decontextualised lessons prepared and implemented according to the requirements of the supervising teacher; or at worst it can be an unsupported and disillusioning experience.

The time had come to re-think school-based practice teaching programs and in late 1997, a small group of our Faculty of Education staff initiated an informal, but searching series of discussions that centered on developing an alternate mode of delivery for the Bachelor of Teaching (Primary) Program. The outcomes of these discussions can be summarised thus:

1. Given that the rapidity at which socio-political change was impacting on all levels of the education system, as teacher educators, we faced a 'double whammy'. Not only was it becoming obvious that schools, more than ever, would need increasing numbers of teachers who were both knowledgeable 'thinkers' and highly flexible' doers', but it would be our responsibility to lay the foundations for their life-long professional growth and development.

2. Like most pre-service teacher education providers we had both anecdotal and empirical evidence which indicated that many of our graduates arrived at schools after graduation very much unaware of how school and classroom cultures operated, were unable to see the relationships between what they had studied in the courses they'd completed, and how it should be translated into effective classroom practice. (Grant, 1994, Armour \& Booth, 1999).

3. We were also aware that the system which employed most of our (and other providers') graduates (the NSW Department of Education [DET]), had a longstanding concern that teacher education graduates in general did not know how to solve the kinds of problems which would confront them on appointment to schools, and that as the main employing authority, they were looking for ways to reduce the cost, both in terms of time and personal stress, of the 'induction period' that many newly graduated teachers seemed to need.

4. After several long, drawn-out 'restructurings', our program evolved to what could be described as an eclectic mix of key features of what Reid and O'Donoghue (2001) refer to as the 'traditional dominant models'. Our model was underpinned by basic, 'non-negotiable skills and knowledge', to which was added layers of a 'teacher-as-skilled artisan' ethos, and this was then wrapped in a mantle of 'standards of professional competency'.

5. Despite this our graduates didn't seem to change in ways that were commensurate with the constantly changing needs of the profession and/or the systems that employed them.

6. We therefore needed to explore, design, trial, and evaluate alternate models of pre-service teacher education 
Given this rationale, the faculty supported a proposal to design a research project that would investigate, as a pilot, an alternative approach to initial teacher education through:

- Implementation and evaluation of an inquiry and problem-solving approach such as that used in medicine and the health sciences; and

- Greater integration of the practical field-based component of the teacher education program with the theoretical.

As a consequence of a wide ranging review of relevant literature we concluded that we needed to begin a process of challenging, and subsequently changing, the traditional paradigm of pre-service teacher education to which we'd been wedded for as long as we cared to remember. We decided that given the complexity of effecting such change, given our particular University/Faculty socio-political context, our best chance for starting and maintaining such a shift would be to design a project which would produce at least the following changes:

- A shift in the mode of program delivery from the traditional' campus-basedlecture-tutorial' mode to a 'problem based-learning-within-a-school-site' mode;

- $\quad$ A shift of from the traditional clinical supervision model of practice teaching to a problem-based-action-research-mentoring model that brought the relationship between the specialised knowledge in Education courses and the nature and culture of schools and how they 'do business', closer together and;

- A shift in the traditional roles and responsibilities the major stake holding groups in teacher development, namely, the professional employing authorities, (e.g. NSW DET, local non-government school systems), the university, local schools, and the Teacher's Unions (NSWTF), so that a new form of 'School-based Learning' might be developed.

We argued that if we set these three processes in motion, an important by-product would be the opportunity to identify and explore the logistical, cultural, and political barriers to effecting changes in:

- $\quad$ The teaching/learning culture of undergraduate teacher education (in our context); and

- The traditional mindset and culture associated with practice-teaching/the practicum, (in our context).

By late 1997 the faculty agreed to support the proposal 'in principle' provided that any structural and/or procedural changes that were set in place were:

- Resource-neutral;

- Maintained academic standards, and met professional standards of competency; and

- Maintained equity of workload and assessment procedures, with respect to students/staff locked into the mainstream program.

This 'in principle' support was followed by a further two years of formal and informal meetings with the major stake-holding groups, including senior management within the NSW DET Directorates, local superintendents, principals, whole-school staffs, 
individual teachers, faculty committees and diverse university power brokers, as well as the teacher unions. In these two years different formal committees, working parties, reference groups met, negotiated and discussed, for an estimated total of 1200 to 1500 hours. By the beginning of the 1999 academic year a pilot program had been designed. We were ready to begin.

\section{Part 2. The Structure of the Knowledge Building Community Program}

It was soon realized that the prospect of implementing a new program with a full cohort of more than 240 incoming first year students, while at the same time maintaining the pipe-line of second, third, and fourth year students who were already enrolled in the existing program, was logistically impossible. We therefore decided to impose two caveats.

Caveat \#1: We would begin with a small sub-group comprising approximately $10 \%$ of the new intake, to a maximum of 24 students; and

Caveat \#2: The KBC model would operate only in those sessions when practice teaching was scheduled, (Session 1 in first and second year, Session 2 in third year). This meant that the $10 \%$ of students who were admitted to participate in the KBC version of the program would be engaged in this form of pre-service professional training for approximately half their total program. For the other half they would join their mainstream peers and engage in the traditional 'lecture + tutorial + formal examination' form of program delivery. Figure 1 below is a schematic representation of this caveat showing the year-by-year progression for the cohort of 24 students who became part of the KBC project, vis-à-vis the other $90 \%$ of their mainstream peers.

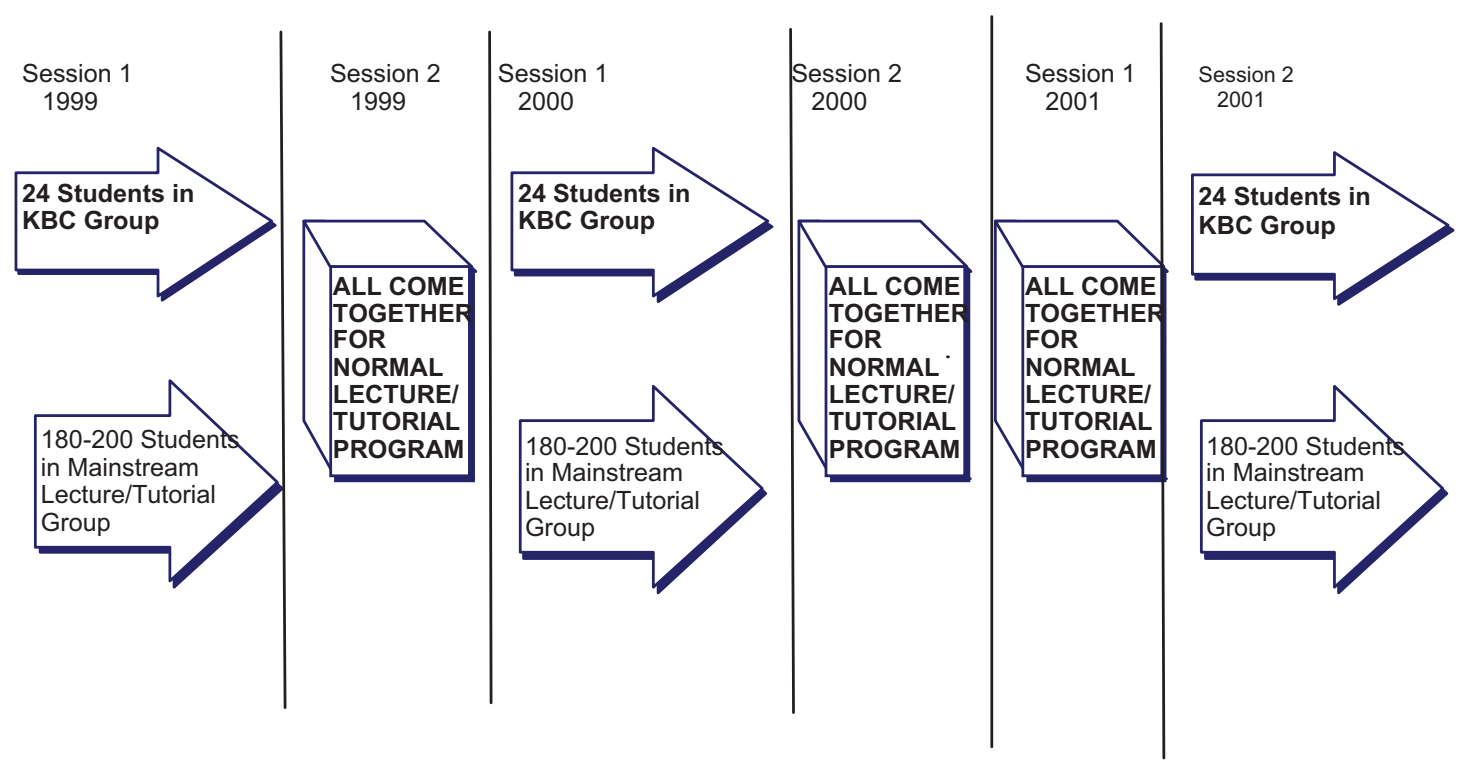

Figure 1:Session-by-Session Progression

With these caveats in place we anchored our alternative model of teacher education to a robust constructivist theoretical model based on a concept by Berieter and Scardamalia (1993) who proposed the concept of a Knowledge Building Community. They described a Knowledge Building Community as a group of individuals dedicated to 
sharing and advancing the knowledge of the collective. Members of this community invest its resources in the collective pursuit of understanding.

The notion of students and teachers working together in collaboration has been in educational conversation since Dewey but in the last decade has been taking a more definite shape in various programs (Scardamalia \& Bereiter, accessed January 2000). These various experimental programs have taken place predominantly in school settings. Scardamalia and Bereiter present the Knowledge Building Community as a means of reforming the culture of the classroom (Hewitt et al, 1995). The adoption of this approach sees the class become a research team aimed at advancing its own "collective, intellectual growth through sustained, collaborative investigations" (Hewitt et al, 1995, p. 1). Based on the principles espoused by Scardamalia and Bereiter (1989, 1991, 1993, 1996) the student teachers involved in the KBC project at the UOW work in a learning environment that supports the continuous social construction of knowledge (Vygotsky, 1978).

The Knowledge Building Community in operation at the UOW is a teacher education model specifically designed to deal with the issue of contextualising the delivery of instruction. One of its important tenets is that instruction should be linked as closely as possible to the contexts and settings to which it applies in the real world. Furthermore KBC's are based on the creation of learning environments that:

i) Support the continuous social construction of knowledge, THROUGH,

ii) The constant construction, de-construction, and reconstruction and sharing of meanings,

SO THAT,

iii) The community's knowledge needs are advanced and maintained

The UOW's KBC applied these principles through the creation of a setting that provided opportunities to engage in three modes of learning:

- Community learning (CL);

- School-based learning (SBL);

- Problem-based learning (PBL)

Community Learning:

Community learning (CL) is a major shift from the traditional teacher education model of lectures and tutorials and serves to strengthen the working link between the University and the participating local primary schools. It requires the development of a community of learners, which is made up of preservice teachers, the school-based teachers and University lecturers who act as facilitators on campus. This community is designed to establish a sense of trust among all of its members who are dedicated to working together to educate and develop competent and sensitive professionals.

\section{School-based Learning:}

School-based learning (SBL) is the second learning principle of the KBC project. Schools are more than a conglomeration of buildings and people rather they are a set of 
individual cultures which have evolved in response to the wider cultural values (Bullough, 1987). To function, and indeed survive a beginning teacher must understand this culture. This component of the KBC structure aims to develop a sophisticated understanding of school-based culture. It is important for preservice teachers to understand how schools do business and how classroom cultures operate and support the learning of all students. It is also necessary as a part of this understanding of classroom culture to know and appreciate how to create and sustain this culture. This part of the KBC project is particularly aimed at reducing the 'reality shock' by increasing preservice teacher's understanding of a teacher's multiplicity of roles in both the school and the classroom.

\section{Problem-based Learning}

Although problem-based learning has been extensively used in medical and other health professions over the last 30 years it has not widely crossed over into teacher education. The literature to support problem-based learning in preservice teacher education provides relatively few examples. Higher education has become characterised by structured subject based learning. Subject based learning has at its centre the lecture. The lecture rates poorly as a means to motivate students because the core issue of the lecture is the lecturer's intent to cover set material (Margetson, 1994). However, effective student learning does not necessarily result from the lecturer's presentation of material. It appears that no matter how well the lecturer performs during the course of the lecture, students still sit passively and are seldom involved (Margetson, 1994). Subject-based learning means that subjects are viewed in isolation from each other and it is the subject that is driving learning. This style of learning assumes that the learner is unknowledgeable (Woods, 1994) and the instructor is the source of knowledge.

Current Problem-based Learning (PBL) theory asserts that PBL encourages and motivates students to 'learn to learn' (Duch, 1995). The critical difference in PBL is that it is characterised by instruction, which involves the students working in small groups to solve 'real world' problems. In this process the students develop skills of negotiation, communication and collaboration (Aldred, Aldred, Walsh \& Dick, 1997). Problem-based learning is believed to promote life-long learning, making knowledge relevant by placing it in context (Aldred et. al., 1997). Above all problem-based learning challenges students to take charge of their education (White, 1996). The common characteristics of PBL are:

- Abolishing the traditional lecture-tutorial format;

- Changing the lecturer's role from transmitter of facts to facilitator of learning; and

- The facilitator will ask open-ended questions, monitor progress, probe and encourage critical reflection, and make suggestions thus helping students to create a positive learning atmosphere.

Duch, (1995), says that faculties that incorporate problem-based learning into their courses empower their students to take a responsible role in their learning and as a result must be ready to yield some of their authority in the classroom to the students. The transition to a PBL mode of delivery should not be considered as an easy option or a quick fix. Just as the tutor needs to adopt changes to practice the students involved in the transition to PBL also go through certain changes and these need to be understood for a smoother transition to PBL for all concerned. Students involved in PBL need to become self-directed learners and it must be realised that the benefits to this mode of 
learning are neither immediate nor automatic, the learning curve required with such an undertaking is very steep.

The students, whose teachers have been telling them everything they needed to know from the first grade on, don't necessarily appreciate having this support suddenly withdrawn. Some students view the approach as a threat, some students may gripe loudly and bitterly about other team members not pulling their weight or about having to waste time explaining everything to slower team mates.

(Felder \& Brent, 1996, pp. 1-2)

Initial glitches involved with implementing PBL are both common and natural (Felder, 1995) and if an understanding about them is present they can be overcome without too much pain, panic or discouragement. These learning principles are represented diagrammatically in Figure 2:

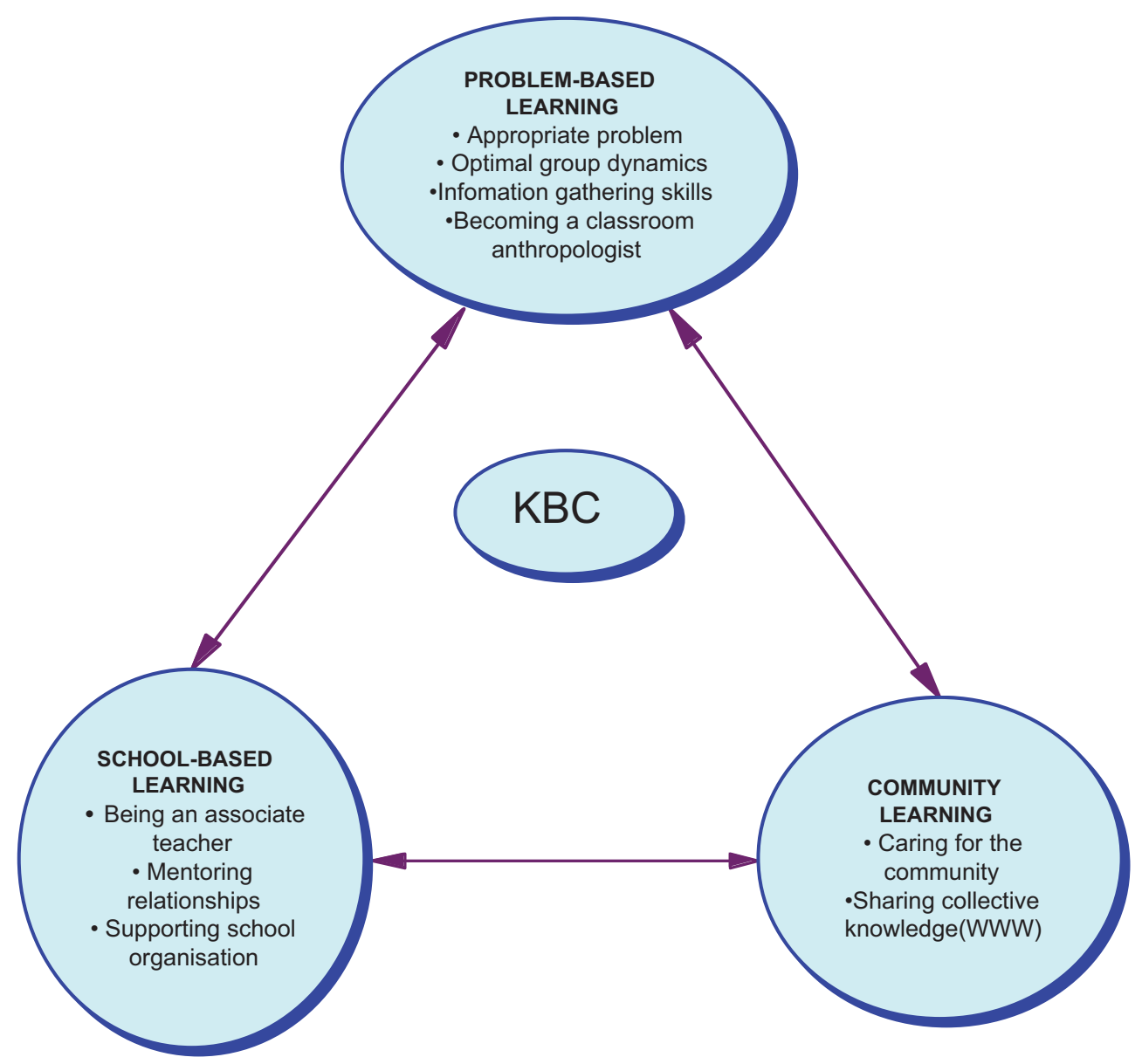

Figure 2: Diagrammatic representation of the KBC's learning principles

\section{The KBC Program: Forging Relationships, Increasing Learner Identity and Responsibility}

As the students work through the above learning principles of the $\mathrm{KBC}$ a tripartite relationship is built. This relationship highlights the importance of social interaction between the main participants. When students are given the opportunity and support of 
the KBC facilitators, school-based teachers and each other they can develop ownership of and responsibility for their own learning. This tripartite relationship is known as the community triad. With the support of this triad students are able to link theory to practice as well as developing an increased understanding of the culture of schools and the way that they operate.

The partnership between university facilitators and school-based teachers meets on eof Ramsey's (2000) recommendations - that the re-energising of teacher education needs to be supported by reconnecting universities and schools. It also demonstrates to the students that they are part of an established team and this team can only become the community triad with their inclusion.

Just as the students had reflected on the relationships that they had established through their involvement in the KBC program so to did the school-based teachers.

Having KBC students in the school has led to discussions about teaching philosophies and organisational matters better professional conversations not whingeing and whining...

Steve

The students were making comments and asking questions that as a teacher I have longed to hear because what it did was reassure me that as graduates they were going to be effective teachers

Jane

Comments such as those above from the school-based teachers involved in the KBCMentoring Program support the existence of the community triad. However the university facilitators also take on this role and their role cannot be underestimated.

The role of $\mathrm{KBC}$ facilitator differs from the traditional role of the lecturer. They take on multiple roles including counsellors, confidantes, co-learners, mediators, and "buffers" between the Community and the University bureaucracy and the school system.

University facilitators are responsible for the coordination of the program, the school liaison and the recruitment of students. In terms of the coordination it is the facilitators' duties to ensure that students meet the outcomes of the subjects in which they are enrolled. This aspect requires meetings with mainstream subject coordinators and lecturers, as well as regular $\mathrm{KBC}$ facilitator meetings that discuss and debrief the students' progress.

\section{The Evolution of Wollongong's KBC Program}

The UOW program has been evolving for almost 5 years now. Although we've had to abandon some of the original organisational and procedural ideals we started with in 1999, the underlying constructivist rationale and philosophy has remained firmly in place.

The current, $2003 \mathrm{KBC}$ model is best described as a: 'negotiated-evaluation- of-a-non-negotiable-curriculum-based-on-aconstructivist-model of-learning-and-knowledge-building'.

This over-nominalised phrase captures the essence of UOW's KBC program since 2001. While the program is still delivered along the original guidelines of the KBC 
ideals (i.e. CL, SBL, and PBL), a significant addition has been the addition of what we call, 'the four pillars of professional wisdom' which now frame and guide the KBC learning process.

These four 'pillars' of UOW's KBC are:

- taking responsibility for mine and others' learning;

- learning through professional collaboration;

- identifying and resolving professional problems; and

- becoming a reflective practitioner.

The four pillars allow students to practice empowerment and responsibility and ultimately enable the integration of the curriculum. Therefore it is important to fully investigate what activities the students need to undertake in each of the four pillars of the KBC.

\section{Taking responsibility for own learning:}

Within pillar number one it is expected that the students will:

- Demonstrate that they understand the importance of becoming autonomous, selfdirected, independent learners

- Demonstrate that they know how to make effective, productive, learning decisions

- Identify a set of learning "strategies" and/or "tactics" that responsible, self-directed, independent learners can use and/or draw on

- Apply some of these strategies and/tactics to their own learning.

\section{Learning through professional collaboration}

Pillar number two expects the students to:

- Demonstrate understanding of the value and power of collaborative learning.

- Demonstrate ability to work productively and professionally as a member of a team.

- Demonstrate the ability to deal with inter-group conflict in productive ways.

- Understand how "group dynamics" work and be able to apply principles and "know-how" to maintain group cohesion.

- Demonstrate that they can collaborate in the generation of professional knowledge which all who are members of the KBC community can share and use

- Understand the difference between "competitive" and "collaborative" learning and know when either is appropriate.

- Actively support each other's and the whole community's learning.

- Be honest, "up-front" and professional with each other, especially with respect to opinions and behaviour of others in the community. (Even if you don't like members of your group you need to show you know how to deal with this in ways that will not destroy or destabilise the learning or problem solving that the group/community is involved in).

\section{Identifying and resolving professional problems}

Pillar number three encompasses the principles of PBL and therefore expects that the students will:

- Demonstrate the ability to identify and articulate professional problems, which need to be addressed and resolved. 
- Demonstrate the ability to analyse the key elements in a range of professional problems.

- Make explicit and apply a set of problem- solving strategies and tactics with can be used to address and resolve such problems.

- Demonstrate the ability to identify resources that might be needed to address and resolve a problem, and subsequently find and use such resources.

- Demonstrate the knowledge and ability to use time effectively in the problemsolving process.

\section{Becoming a reflective practitioner}

The fourth and final pillar of KBC learning engages the students in reflective practice; therefore the students will be carrying out the following activities:

- Demonstrate the ability to engage in the process(es) inherent in reflective learning

- Students will be expected to make regular, honest, and systematic judgements of the degree to which they believe they have demonstrated the four broad specific outcomes of $\mathrm{KBC}$ in the various settings (School, KBC home-room, and via SelfDirected Learning).

The four pillars of the KBC are a set of complex interactions that are interrelated. When these interactions are working they will serve to drive any assessment task that is to be investigated. When the expectation that all members of the $\mathrm{KBC}$ have to acquire skills in using, and demonstrating conceptual understanding of these four 'pillars' is made explicit, it sets in train a range of complex interactions within the KBC.

Figure 3 below describes the relationships between the 4 pillars of professional learning, processes and structures inherent in the $\mathrm{KBC}$ process, and how these are distributed across the session to allow for the creation of an integrated curriculum. 


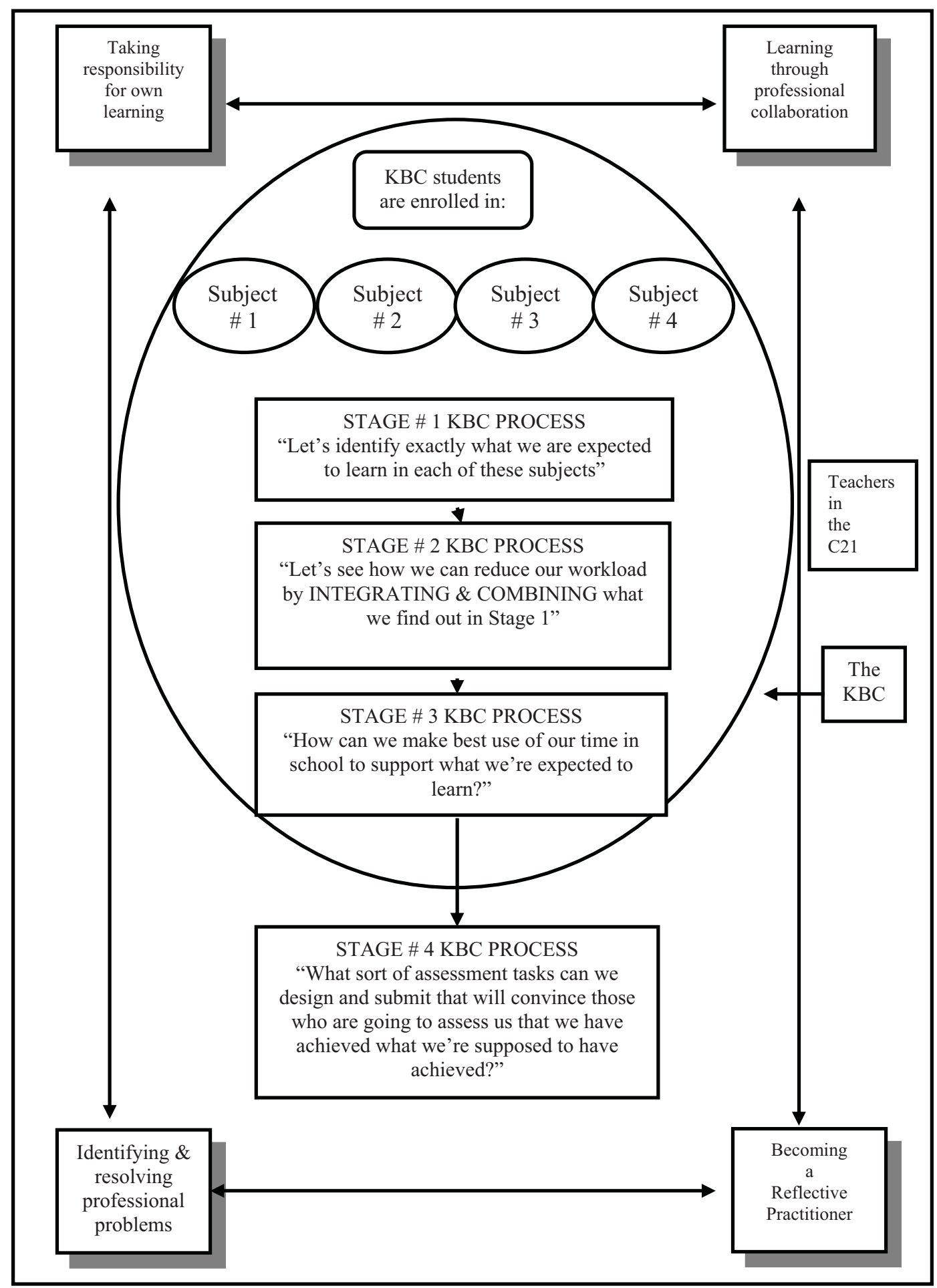

Figure 3: The Four Pillars of Professional Learning \& the KBC Processes and Structures of Integration

\section{Integrating the knowledge bases across the university curriculum}

The KBC models of 1999 and 2000 had large overarching problem-based learning style assessment tasks that had been written in an attempt to meet the requirements of the compulsory subjects. These problems proved cumbersome and in the end served only to hinder the learning of the students. In the Figure 3 it is shown that the Four Pillars of 
Professional Learning are also supported by a series of four questions which have been designed to guide the students in their quest to master the outcomes of the compulsory subjects in which they were enrolled. These four questions were intended to guide students as they worked towards designing their own assessment tasks. The four guiding questions as shown in Figure 3 are:

| Stage 1 "Let's identify exactly what we are expected to learn in each of these subjects"

| Stage 2 "Let's see how we can reduce our workload by integrating and combining what we find out in Stage 1"

\ Stage 3 "How can we make best use of our time in school to support what we're expected to learn?"

〔 Stage 4 "What sort of assessment tasks can we design and submit that will convince those who are going to assess us that we have achieved what we're supposed to have achieved?"

It is timely to investigate what processes the students carry out at each stage/guiding question in order to achieve subject integration:

\section{Stage 1: "Let's identify exactly what we are expected to learn in each of these subjects"}

At stage one the KBC students are expected to deconstruct the subject outlines for each of their enrolled subjects. This process will highlight each subject's outcomes. The students will then be able to compare each subject for commonalities. In 2002 this process revealed that the compulsory subjects of Language and Literacy, Curriculum and Pedagogy I and Education 1 required that students "read and demonstrate understanding of specified theory and knowledge; describe examples of how the specified theory and knowledge is applied in practice; demonstrate progress in developing the skills and values needed to become a reflective practitioner". The deconstruction process then revealed that the major themes of these subjects were classroom management and discipline, developing a teaching Program (Curriculum), creating, implementing and evaluating daily lesson plans; assessment and evaluation of student learning theories of child growth and development including physical, social, emotional, psychological, learning, and cognitive growth. Once this stage is complete the students are now ready to identify how these theories and themes relate to teaching, learning and classrooms.

\section{Stage 2: Let's see how we can reduce our workload by integrating and combining what we find out in Stage 1"}

In regards to the students' findings at stage one the KBC 1 groups discuss, question and brainstorm different school-based research that will illuminate the practice behind the theory. The facilitators then take the students to the next level where they ask them to consider the type of actions and resources that could be involved in addressing their fledgling ideas. Questions are posed to the students such as: "What kinds of actions/ activities / tasks etc would you need to engage in to address your assessment plan?" The students are asked to think and plan how they can organise themselves to maximise their learning and minimise their stress, they are asked to consider what kinds of 
collaborative processes and structures they could create and set up and use to ensure that they make full use of the KBC opportunities and resources.

As well as considering how they may undertake their in school investigations the students must consider what options they have for presenting the results of their schoolbased research.

\section{Stage 3 "How can we make best use of our time in school to support what we're expected to learn?"}

The following is a summary of how the one school group planned to link the main concepts and themes of their subjects to their school-based experiences.

In school and self-directed learning as a group we need to take the opportunity to:

$\int$ Read and summarise the text books

Plan and allocate tasks for each group member

Appoint a student subject coordinator to keep track of the data we are collecting

\Make sure we see and experience all the different stages at school

$\int$ Ask our mentor teachers lots of questions

Keep minutes of group meetings

Record our definitions and our brainstorm lists

$\lceil$ Share them with the rest of the KBC group

Stage 4: "What sort of assessment tasks can we design and submit that will convince those who are going to assess us that we have achieved what we're supposed to have achieved?"

The following is an example of one group's planned responses for the compulsory subjects:

\section{Curriculum \& Pedagogy}

After the students had analysed the subject outlines, compulsory texts and consulted with the $\mathrm{KBC}$ facilitators they proposed that the core components for this subject were:

- Classroom management and discipline

- Developing a Program (Curriculum)

- Daily Lesson Planning and Evaluation

- Assessment \& Evaluation of Student Learning.

Based on this analysis they proposed to address these following three questions:

1. What do teachers at our school believe about each of these components?

2. What practical examples of these beliefs did we witness, or hear about while at the school?

3. Describe some of our own experiences with each of these components in our roles as a Teacher Associates

4. What links can we make between what we find out in $1,2,3$, and the prescribed textbook 


\section{Education 1}

The students proposed to carry out a mini-research project which addressed these two questions:

1. What is the link between the theories of growth \& development described in the prescribed text and real primary school children?

2. What do the different theories of learning/ cognitive development described in the prescribed text book (Piaget, Vygotsky, Gardner,) actually look like in the classroom?

\section{Language and Literacy}

The KBC students proposed that the core components of Language and Literacy were:

$\int$ The content of the official NSW K-6 English Syllabus

[ The content of the prescribed text book

Identifying how theory is put into practice especially in the early years

$\lceil$ The links we can make between what we find out in 1, 2, \& 3 above and our own SBL experiences, through the processes of individual \& group reflection"

Figure 5 shows how this group integrated their assessment tasks. It is a summary of the processes that they followed as they developed their final set of assessment tasks based on the above proposals.

The final product was based upon the organizational metaphor of a "Reading Programcum-Library Box" reflecting a very effective home-school reading program, which is a special feature of the school that they were at. The artifacts and documentation included in the final product were a set of documents which recorded the reading, writing, collaboration, research, and connections between theory and practice which the group made while at the school during their school-based learning time. This assignment consisted of7 bound books. Three were an integrated Education 1 and Language and Literacy compilation and consisted of a total of 127 pages. Four were labeled Curriculum and Pedagogy and consisted of 102 landscape pages of matrices of observations and links to other core subjects. The students also included a volume devoted to appendices and artifacts.

Also included in the 'library' was a key document which outlined the processes and responsibilities of each of the members of the group. Within this document there were details that highlighted how the group

1. Negotiated an equitable group contract.

2. Created and refined structures, roles, and responsibilities to ensure workload was completed in ways that resulted in a knowledge-collective that each group member "owns" and internalises.

3. Negotiated with the school regarding how they aligned assessment tasks with school needs 


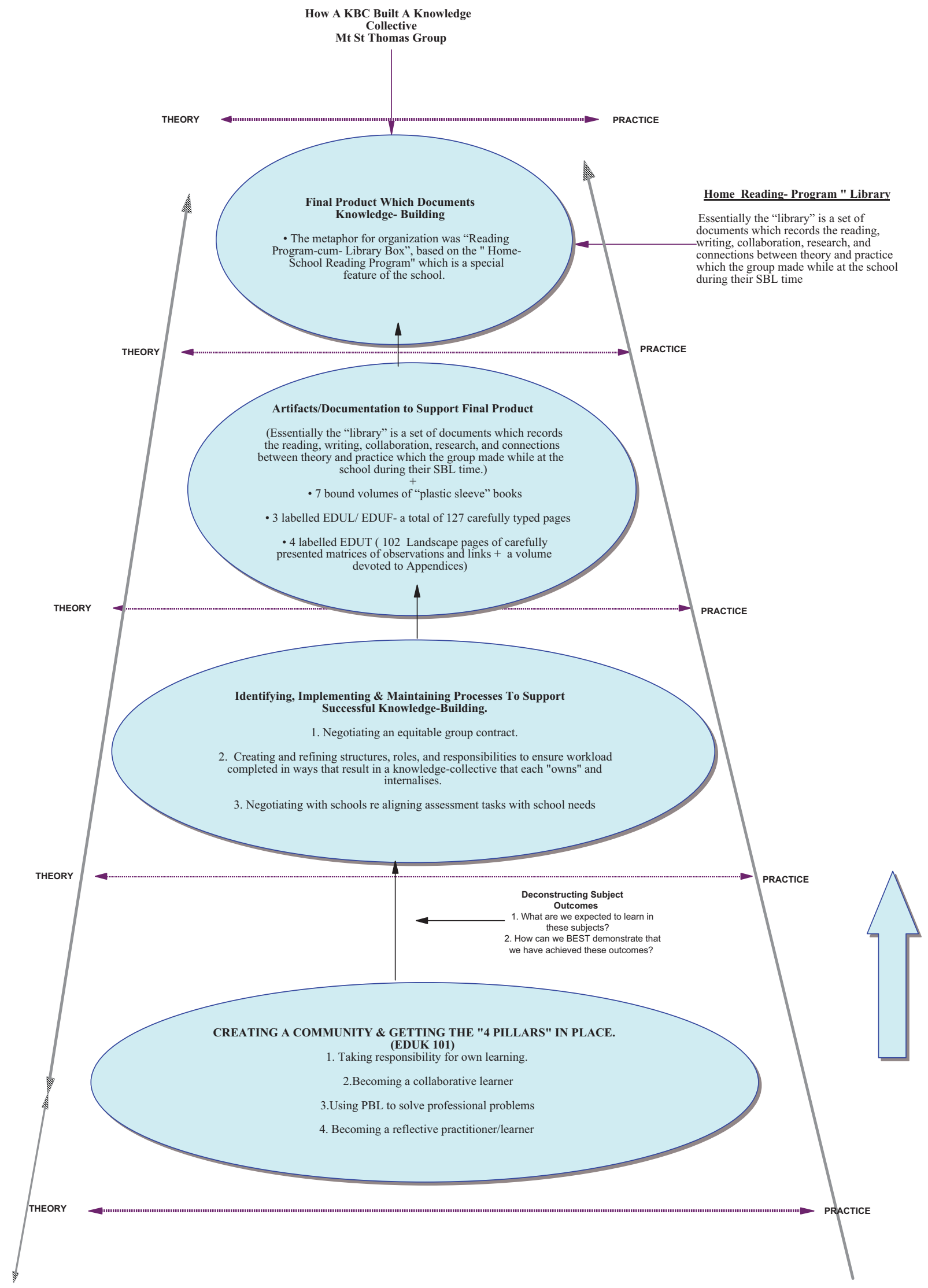

Figure 4: The knowledge integration process. 


\section{Maintaining Quality Control}

The purpose of the guiding questions serves to focus student attention so that they develop learning tasks that meet the compulsory requirements for individual subjects. The form of any facilitator guidance takes, is dependent upon the maturity and experience of the students. Often the facilitators' responses are often in the form of feedback on the students' plans or via probing questions designed to highlight weaknesses in their plans. Often the wording of these questions was critical to the success of the next stage of the process and time and thought must be devoted to the wording of these questions.

In addition students and facilitating lecturers consulted with subject co-ordinators to receive critical feedback on proposed tasks. This ensured that the tasks meet the expectations of all stakeholders. Further, each $\mathrm{KBC}$ group was given the opportunity to convince a critical audience of experienced staff of the quality of their work at a final presentation day held at the end of the session.

\section{Concluding Comments}

We believe that the KBC process acts as a stimulus for the achievement of one of the long-term goals of most teacher education courses i.e. a strong commitment to life-long professional learning. The four pillars together with the four-stage approach to curriculum integration provide a set of structures, processes, and a form of discourse for KBC students, university facilitators and participating school-based teachers. This discourse assists all participants in on-going construction and refinement of understandings about their role(s) in the profession and of the transformative nature of their profession. To achieve this they need to be involved in ongoing discourse that will both challenge and affirm strongly held knowledge and beliefs. Such a process requires participants to be exposed to opposing views and alternatives to 'accepted' practices. Thus participants are exposed to a wide range of information and views about what teachers know, do expect and value and this has the potential to significantly influence the nature, extent and rate of future learning of their pupils. In addition the process stimulates all stakeholders to explore innovative approaches to learning and assessment in a university context that is increasingly regulated by stringent quality controls.

During their careers in education graduates of teacher education courses will be continually challenged to revisit many of the issues initially raised during their undergraduate course. We believe that the principles of professional learning that were articulated and experienced through the four pillars model of the $\mathrm{KBC}$ will serve as a scaffold allowing graduates to re-apply the principles and processes used in the undergraduate degree to the professional context of the full-time classroom teacher. Further, if the KBC process is achieving its stated goals, we should be able to observe that graduates are applying such processes in their professional lives.

Finally, it is important to restate that there are many education faculties throughout the world who are experimenting with alternative approaches to teacher education and our story represents one contribution to this growing body of knowledge about alternative approaches to initial teacher education. Indeed our own faculty has adapted the processes described in this chapter to trial an integrated assessment approach with the entire first-year primary education intake in 2004. 


\section{References:}

Aldred, S. E., Aldred, M. J., Walsh, L. J., \& Dick, B. (1997). The direct and indirect costs of implementing problem-based learning into traditional professional courses within universities. Department of Employment, Education Training and Youth Affairs: Australia.

Armour, L., \& Booth, E. (1999). Analysis of a questionnaire to primary educators at schools accepting students for the six week extended practicum. Report by Faculty of Education: University of Wollongong.

Bereiter, C. \& Scardamalia, M. (1993). Surpassing ourselves. Open Court. Illinois.

Bransford, J. D., Sherwood, R. D., Hasselbring, T.S., Kinzer, C.K., \& Williams S.M. (1990). Anchored Instruction: Why we need it and how technology can help. In D. Nix \& R. Spiro (Eds.) Cognition, Education Multimedia: Exploring ideas in high technology. Hillsdale:Lawrence Erlbaum, 115-141.

Bullough, R. V. (1987). Accommodation and tension: Teachers, teacher role, and the culture of teaching. In: J. Smyth. Educating teachers: Changing the nature of pedagogical knowledge. (pp. 83-94). London: The Falmer Press.

Commonwealth of Australia (2002). An Ethic of Care - Effective Programmes for Beginning Teachers. Canberra: DEST.

Darling-Hammond, L. (1999). Teacher Education: Rethinking Practice and Policy. Unicorn 25(1), 31-48.

Duch, J. B. (1995). What is Problem-Based Learning? from The Newsletter for the for the Centre for Teaching Effectiveness, University of Delaware.

Available URL: http://www.udel.edu/pbl/cte/jan95-what.html. Accessed: 29/03/98.

Entwhistle, N., Entwhistle A., \& Tait H.(1993). Academic Understanding and the Contexts to Enhance It: A perspective from research on student learning. In T.M. Duffy, J.Lowyck \& D.H. Jonassen (Eds.) Design Environments for Constructive Learning.Heidelberg: Springer-Verlag, 331-357.

Felder, R. M., \& Brent, R. (1996). Navigating the bumpy road to student-centred instruction. Available URL:

http://www2.ncsu.edu/unity/lockers/users/f/felder/public/Papers/Resist.html.

Accessed: 28/07/00.

Grant, L. M. (1994). An evaluation of the effectiveness of preservice language education in one university Unpublished Honours Thesis, Faculty of Education, University of Wollongong. University of Wollongong: Australia.

Groundwater-Smith, S., Deer, C. E, Sharp, H. \& March, P (1996). The Practicum as Workplace Leaning: A Multi-Modal Approach in Teacher Education. Australian Journal of Teacher Education, 22(2), 21-30. 
Hoban, G. H. (1999). In press Using a metacognitive framework to guide experiential learning in teacher education classes. Journal of Experiential Education TO CHECK

Koetsier, C. P. \& Wubbels, J. T. (1995). Bridging the gap between initial teacher training and teacher induction. Journal of Education for Teaching. Vol. 21. No. 3. pp 333-345.

MACQT, (1998). Teacher preparation for student management: Responses and directions. Report by Ministerial Advisory Council on the Quality of Teaching, October, 1998. Sydney: NSW Department of Education and Training.

Margetson, D. (1994). Current educational reform and the significance of problembased learning. Griffith University: Carfax Publishing Company.

Ramsey, G. (2000). Quality matters. Revitalising teaching: critical times, critical choices. NSW Department of Education and Training: Sydney.

Reid, A., \& O’Donoghue, M. (2001). Rethinking Teacher Education Policy. Paper presented at Australian Teacher Education Association Conference. 24-26 September. Melbourne.

Scardamalia, M., \& Bereiter, C. (1999) Schools as knowledge building organisations. Available URL: http://csile.oise.utoronto.ca/abstracts/ciar-understanding.html Accessed: 08/01/00.

Scardamalia. M., \& Bereiter, C. (1991). Higher levels of agency for children in knowledge building: A challenge for the design of new knowledge media. The Journal of the Learning Sciences, 1 (1), 37-68.

Scardamalia. M., \& Bereiter, C. (1993). Surpassing ourselves: An inquiry into the nature and implications of expertise. Chicago: Open Court.

Scardamalia. M., \& Bereiter, C. (1996). Student communities for the advancement of knowledge. Communications of the ACM, 39 (4), 36-37.

Vygotsky, L. (1978). Mind in Society: The development of higher psychological processes. Cambridge: Harvard University Press.

White, H. (1996). Dan tries problem-based learning: A case study. Available URL: http://www.udel.edu/pbl/dancase3.html. Accessed: 29/03/99.

Woods, D. (1994). How to gain the most from problem-based learning. McMaster University: McMaster.

Vinson, T (2002). Report of the Independent Inquiry into Public Education in New South Wales. NSW Government: Sydney. 